\title{
Comparing baseline and longitudinal measures in association studies
}

\author{
Shuai Wang ${ }^{1 *}$, Wei Gao', Julius Ngwa', Catherine Allard² ${ }^{1}$ Ching-Ti Liu', L Adrienne Cupples ${ }^{1}$ \\ From Genetic Analysis Workshop 18 \\ Stevenson, WA, USA. 13-17 October 2012
}

\begin{abstract}
In recent years, longitudinal family-based studies have had success in identifying genetic variants that influence complex traits in genome-wide association studies. In this paper, we suggest that longitudinal analyses may contain valuable information that can enable identification of additional associations compared to baseline analyses. Using Genetic Analysis Workshop 18 data, consisting of whole genome sequence data in a pedigree-based sample, we compared 3 methods for the genetic analysis of longitudinal data to an analysis that used baseline data only. These longitudinal methods were (a) longitudinal mixed-effects model; (b) analysis of the mean trait over time; and (c) a 2-stage analysis, with estimation of a random intercept in the first stage and regression of the random intercept on a single-nucleotide polymorphism at the second stage. All methods accounted for the familial correlation among subjects within a pedigree. The analyses considered common variants with minor allele frequency above $5 \%$ on chromosome 3. Analyses were performed without knowledge of the simulation model. The 3 longitudinal methods showed consistent results, which were generally different from those found by using only the baseline observation. The gene CACNA2D3, identified by both longitudinal and baseline approaches, had a stronger signal in the longitudinal analysis $\left(p=2.65 \times 10^{-7}\right)$ compared to that in the baseline analysis $\left(p=2.48 \times 10^{-5}\right)$. The effect size of the longitudinal mixed-effects model and mean trait were higher compared to the 2-stage approach. The longitudinal results provided stable results different from that using 1 observation at baseline and generally had lower $p$ values.
\end{abstract}

\section{Background}

Longitudinal data analyses are widely used in genomewide association studies to assess genetic and environmental risk factors and their association with phenotypes of interest [1-3]. They are more complicated than analyses using only baseline measures because subjects are followed over time and change is measured during follow-up. Standard linear regression techniques are not applicable in this setting because of the correlation that exists among the repeated measures per subject. Methods for longitudinal study designs have enabled the investigation of genetic variation influencing trait values over time [3]. In Genetic Analysis Workshop 13, Gauderman et al [4] provided an overview of a wide range of methods for

\footnotetext{
* Correspondence: tutuwang@bu.edu

'Department of Biostatistics, Boston University School of Public Health, 801

Massachusetts Avenue 3rd floor, Boston, MA 02118, USA

Full list of author information is available at the end of the article
}

the genetic analysis of longitudinal data in families. They summarized these methods into 2 groups: (a) 2-stage approaches, in which a summary statistic is obtained and used in genetic analysis, and (b) joint modeling, in which the genetic and longitudinal data are analyzed simultaneously in a single analysis. They argued that the use of a mean-type statistic could provide greater power compared to a slope-type statistic for detecting a gene effect. Zhu et al [1] performed a genome-wide association in which they identified genes and gene-environment interactions associated with longitudinal traits. They implemented a multivariate adaptive spline for the analysis of the longitudinal data.

In this paper, our main object is to compare existing methods of longitudinal data analyses with those that use only 1 baseline measure in association studies. We explore the following longitudinal methods: (a) a longitudinal mixed-effects model; (b) analysis of the mean trait 
over time; and (c) a 2-stage analysis, with estimation of a random intercept in the first stage and regression of the random intercept on a single-nucleotide polymorphism (SNP) in the second stage. These longitudinal methods use statistics that capture the level of a trait, such as a mean, to detect genetic associations as opposed to methods that focus on the change in the trait over time, such as a slope. Despite the strengths and integrated approach of a longitudinal mixed model, its implementation is very computer-intensive because of its complex structure. Therefore, the main motivation for trying some "simpler" alternative longitudinal models, such as analysis of the mean trait over time and a 2-stage analysis, is to see if they can serve as good substitutes with equally good performance.

\section{Methods}

\section{Study subjects and phenotype}

We used real phenotype data collected in the San Antonio Family Heart Study, including sex, age, year of examination, systolic and diastolic blood pressure, use of antihypertensive medications, and tobacco smoking at up to 4 time points for 939 subjects in 20 pedigrees. Of the 939 participants, 244 attended only 1 exam; for the remaining subjects, the median follow-up time was 11 years with a median gap time between assessments of 5 years. We analyzed 2 continuous traits: systolic blood pressure (SBP) and diastolic blood pressure (DBP). For participants on medication, we imputed both SBP and DBP to mimic what their unmedicated values would be. If a subject was on medications at an exam, we imputed the blood pressure at this exam to be the average blood pressure of all observations with higher values among those of the same gender and \pm 10 years of the age of the subject. We performed a preliminary analysis to select covariates for both SBP and DBP. Variables significantly associated $(p<0.05)$ with SBP or DBP were selected. For SBP, we adjusted for age, sex, and tobacco smoking. For DBP, we adjusted for age, sex, tobacco smoking, and centered age squared.

\section{Genetic data}

The genetic data from Genetic Analysis Workshop 18 (GAW18) consisted of whole genome sequence data in a pedigree-based sample with longitudinal phenotype data for hypertension and related traits. A total of 26.8 million SNPs were identified in the 483 individuals. After eliminating 19 outlier individuals who failed to meet SNP quality control criteria such as fractions and ratio of homogeneous and heterogeneous sites and fraction of novel SNPs, 24 million SNPs passed support vector machine and indel proximity filters. Genotype calls cleaned of mendelian errors and dosages were provided for 959 individuals (464 directly sequenced and the rest imputed) for $8,348,674$ locations in the genome.
A majority of the SNPs were rare variants; $51 \%$ had a minor allele frequency (MAF) below 1\%. As suggested by GAW18 leaders, all analyses for this current paper were based on 402,985 common variants (MAF $\geq 5 \%$ ) of chromosome 3 only, accounting for around one-third of the total number of variants on the chromosome.

\section{Statistical analyses \\ Baseline association analysis}

For comparison with the methods that used the longitudinal data, we applied a baseline association analysis that considered only the first observation (baseline) for each person. In addition to adjusting for covariates, we incorporated a familial correlation structure (kinship coefficient matrix) into the model as $Y_{i j 0}=\beta_{0}+X_{i j 0} \beta+\beta_{s} S N P_{i j}+\alpha_{i j}+\varepsilon_{i j}$, where $i$ denotes the $i^{\text {th }}$ pedigree, and $j$ denotes the $j^{\text {th }}$ individual in the $i^{\text {th }}$ pedigree. For this individual, $Y_{i j 0}$ denotes the phenotype at baseline, $X_{i j 0}=\left(X_{i j 01}, \ldots, X_{i j 0 m}\right)$ denotes the covariates at baseline, and $S N P_{i j}$ denotes the SNP dosage. $\beta_{0}$ is the fixed intercept, $\beta=\left(\beta_{1}, \beta_{2}, \ldots, \beta_{m}\right)^{\prime}$ is a vector of regression coefficients for the $m$ covariates, and $\beta_{s}$ is the SNP effect size; $\alpha_{i j}$ is the random intercept for the $(i, j)^{\text {th }}$ person. Within each pedigree, the vector $\alpha_{i}=\left(\alpha_{i 1}, \ldots, \alpha_{i n_{i}}\right)$ is normally distributed with a mean of 0 and a covariance matrix of $\sigma^{2} \Sigma_{k i n}$ (the kinship matrix), contributing a diagonal block for each pedigree to the overall covariance matrix; $\varepsilon_{i j}$ is an error term with a mean of 0 and a variance of $\sigma_{\varepsilon}^{2}$. This model was implemented using the lmekin package in R (version 2.9.2) package "kinship" [5], which employed maximum likelihood methods to estimate parameters.

The notations of $\beta_{0}, \beta, \beta_{s}, S N P_{i j}, \alpha_{i j}, \varepsilon_{i j}$ used in this baseline model apply to the following models where applicable.

To compare with the baseline approach, we considered 3 approaches for longitudinal analyses of these data: (a) longitudinal mixed-effects association analysis, (b) mean measure in longitudinal association analysis, and (c) 2-stage longitudinal association analysis.

\section{Longitudinal mixed-effects association analysis}

We used a random-intercept mixed effects model with familial correlation structure [7]. The model is:

$$
Y_{i j t}=\beta_{0}+X_{i j t} \beta+\beta_{s} S N P_{i j}+\alpha_{i j}+\varepsilon_{i j}
$$

Here $i$ denotes the $i^{\text {th }}$ pedigree, and $j$ denotes the $j^{\text {th }}$ individual in the $i^{\text {th }}$ pedigree. For this individual, $Y_{i j t}$ denotes the trait at time point $\mathrm{t} ; X_{i j t}=\left(X_{i j t 1}, X_{i j t 2}, \ldots, X_{i j t m}\right)$ denotes the covariates at time $t$, including time-dependent covariates. This model was implemented in the $\mathrm{R}$ (version 2.15.1) package "pedigreemm" [6], which used the method of restricted maximum likelihood for parameter estimation.

\section{Mean measure in longitudinal association analysis}

We also considered the mean across all time points as the trait and its corresponding averaged covariates as 
one alternative for longitudinal association analysis. This model is:

$$
Y_{i j}^{*}=\beta_{0}+X_{i j}^{*} \beta+\beta_{s} S N P_{i j}+\alpha_{i j}+\varepsilon_{i j}
$$

Here $i$ denotes the $i^{\text {th }}$ pedigree, and $j$ denotes the $j^{\text {th }}$ individual in the $i^{\text {th }}$ pedigree. For this individual, $Y_{i j}^{*}$ denotes the mean trait across time. $X_{i j}^{*}=\left(X_{i j 1}^{*}, X_{i j 2}^{*}, \ldots, X_{i j m}^{*}\right)$ denotes the covariates, which for time-dependent covariates is the average measure across time.

This model was implemented using the function lmekin in R (version 2.9.2) package "kinship" [5], using maximum likelihood methods to estimate parameters.

\section{Two-stage longitudinal association analysis}

Another longitudinal approach employs a 2-stage strategy [4]. In the first stage, a random intercept, $\alpha_{\mathrm{ij}}$ as the level of the trait for each person was generated from a growth curve model:

$$
\mathrm{Y}_{\mathrm{ijt}}=\beta_{10}+\mathrm{X}_{\mathrm{ijt}} \beta+\alpha_{\mathrm{ij}}+\varepsilon_{\mathrm{ij}}
$$

Here $i$ denotes the $i^{\text {th }}$ pedigree, and $j$ denotes the $j^{\text {th }}$ individual in the $i^{\text {th }}$ pedigree. For this individual, $\mathrm{Y}_{\mathrm{ijt}}$ denotes the trait at time point t. $\mathrm{X}_{\mathrm{ijt}}=\left(\mathrm{X}_{\mathrm{ijt} 1}, \mathrm{X}_{\mathrm{ijt} 2}, \ldots, \mathrm{X}_{\mathrm{ijtm}}\right)$ denotes the covariates including time-dependent covariates. $\beta_{10}$ is the fixed intercept of the first stage; $\alpha_{\mathrm{ij}}$ is the random intercept. As above, the covariance structure of $\alpha_{\mathrm{ij}}$ is $\sigma^{2} \Sigma_{\text {kin, }}$, which contributes a diagonal block for each pedigree to the overall covariance matrix.

In the second stage, random intercept $\alpha_{\mathrm{ij}}$ is treated as the "new" trait and regressed on a SNP as follows:

$$
\alpha_{i j}=\beta_{20}+\beta_{s} S N P_{i j}+\gamma_{i j}+\varepsilon_{i j}
$$

Here $\mathrm{SNP}_{\mathrm{ij}}$ denotes the SNP dosage. $\beta_{20}$ is the intercept of the second stage; $\beta_{\mathrm{s}}$ is the SNP effect size; $\varepsilon_{i j}$ is an error term with a mean of 0 and a variance of $\sigma_{\varepsilon}^{2}, \gamma_{i j}$ is the random intercept that adjusts for the familiar correlation of $\alpha_{i j}$; and, similarly, the vector $\gamma_{i}=\left(\gamma_{i 1}, \ldots, \gamma_{i n_{i}}\right)$ is normally distributed with a mean of 0 and a covariance matrix of $\sigma_{\gamma}^{2} \Sigma_{k i n}$, contributing a diagonal block for each pedigree to the overall covariance matrix.

Gauderman et al [4] pointed out that a mean-based statistic is more powerful to detect a genetic association than a slope-based statistic (eg, a random slope). So here we adopted the random intercept of the first stage rather than the random slope as the "trait" in the second stage. The first-stage model was implemented using lmekin of the R (version 2.15.1) package "coxme" [6], which could handle more than 1 random effect; the second-stage model was implemented using lmekin of the $R$ (version 2.9.2) package "kinship"[5], which adopted a faster computing algorithm. Both packages used maximum likelihood in parameter estimation.

\section{Power and type I error}

We conducted power calculations for all 4 methods and evaluated type I error by means of the genomic control value. We chose the variant (chromosome 3: 47956424) on gene MAP4, the top variant influencing simulated SBP and DBP, as the functional variant for power calculations. To determine power, we tested the null hypothesis that the trait SBP was not associated with the functional variant, versus the alternative hypothesis that it is associated. Therefore, results would be considered statistically significant if the $p$ value obtained using the analysis methods fell below a predetermined threshold. Here we divided the significance level 0.05 by the approximate number $(25,676)$ of independent SNPs on chromosome 3 to adjust for multiple testing. We used PLINK (http://pngu.mgh.harvard.edu/ purcell/plink/) [8] to prune out SNPs on chromosome 3 where the pairwise linkage disequilibrium was 0.2 or greater, and 25,676 SNPs remained. For each of the 4 methods, the estimated power was the proportion of replicates in which the method detected a significant association between the trait and the functional variant.

For each of the 4 methods, genomic control value was used to assess the extent of the inflation of type I error, based on the $p$ value of common variants on chromosome 3.

\section{Results}

\section{Association analysis of real data}

For SBP, there were no shared results in the top 10 hits between the baseline approach and the other 3 longitudinal methods (Table 1). Some shared genes identified by the longitudinal methods were FGF12 and FHIT. The mean measure and 2-stage methods yielded similar results. For DBP, the 3 longitudinal methods yielded consistent results (as shown in Figure 1, right side): the top 10 hits came from the same gene (CACNA2D3 in Table 2; eg, SNP 3_54748234 has a $p$ value of $2.65 \times 10^{-7}$ ), with SNPs nearly reaching a Bonferroni significance threshold. This gene was also found using the baseline method but was less significant (rank $=2, p=2.76 \mathrm{E}-05$ in Table 2).

\section{Power and type I error}

Power was computed to assess the baseline method and the 3 longitudinal methods (Table 3). The 3 longitudinal methods had at least $10.5 \%$ higher power than the baseline method. Among the longitudinal methods, the power of both mean measure and 2-stage methods was comparable ( $41 \%$ and $40.5 \%$, respectively) and substantially higher than that of the linear mixed-effects (LME) method (32.5\%). None of the 4 methods showed elevated type I error because the genomic control value ranged from about 0.98 to 1.034 . 
Table 1 TOP 10 hits of SBP on chromosome 3 across the baseline method and the 3 longitudinal methods

\begin{tabular}{|c|c|c|c|c|c|c|c|c|c|c|c|c|c|c|c|c|c|c|c|}
\hline \multicolumn{5}{|l|}{ Baseline } & \multicolumn{5}{|l|}{ Longitudinal } & \multicolumn{5}{|c|}{ Mean measure } & \multicolumn{5}{|l|}{ Two-stage } \\
\hline SNP & $\begin{array}{l}\text { Effect } \\
\text { size }\end{array}$ & $\mathrm{SE}$ & $P$ & $\begin{array}{l}\text { Closest* } \\
\text { genes }\end{array}$ & SNP & $\begin{array}{l}\text { Effect } \\
\text { size }\end{array}$ & SE & $P$ & $\begin{array}{l}\text { Closest* } \\
\text { genes }\end{array}$ & SNP & $\begin{array}{l}\text { Effect } \\
\text { size }\end{array}$ & SE & $P$ & $\begin{array}{l}\text { Closest* } \\
\text { genes }\end{array}$ & SNP & $\begin{array}{l}\text { Effect } \\
\text { size }\end{array}$ & SE & $P$ & $\begin{array}{l}\text { Closest* } \\
\text { genes }\end{array}$ \\
\hline 3_149871159 & 5.31 & 1.22 & $\begin{array}{l}1.63 \mathrm{E}- \\
05 \\
\end{array}$ & LOC646903, & 3_106220130 & -4.36 & 1.02 & $\begin{array}{l}2.16 \mathrm{E}- \\
05 \\
\end{array}$ & LOC100302640 & 3_106220130 & -4.68 & 1.05 & $\begin{array}{l}9.16 \mathrm{E}- \\
06\end{array}$ & $B C H E$ & 3_165046920 & 2.96 & 0.68 & $\begin{array}{l}1.33 \mathrm{E}- \\
05\end{array}$ & SLITRK3 \\
\hline 3_133160911 & 4.02 & 0.93 & $\begin{array}{l}1.83 \mathrm{E}- \\
05\end{array}$ & BFSP2 & 3_113652027 & 3.77 & 0.89 & $\begin{array}{l}2.34 \mathrm{E}- \\
05\end{array}$ & GRAMD1C & 3_106220437 & -4.65 & 1.05 & $\begin{array}{l}1.06 \mathrm{E}- \\
05\end{array}$ & FGF12 & 3_59966975 & 2.52 & 0.58 & $\begin{array}{l}1.59 \mathrm{E}- \\
05\end{array}$ & FHIT \\
\hline 3_149894219 & 5.10 & 1.22 & $\begin{array}{l}3.41 \mathrm{E}- \\
05\end{array}$ & LOC646903, & 3_106217172 & -4.33 & 1.03 & $\begin{array}{l}2.57 \mathrm{E}- \\
05\end{array}$ & LOC100302640 & 3_106217172 & -4.66 & 1.05 & $\begin{array}{l}1.07 \mathrm{E}- \\
05\end{array}$ & FGF12 & 3_192240010 & -3.67 & 0.86 & $\begin{array}{l}2.14 \mathrm{E}- \\
05\end{array}$ & FGF12 \\
\hline 3_122390279 & 5.24 & 1.26 & $\begin{array}{l}3.65 \mathrm{E}- \\
05\end{array}$ & PARP14 & 3_165046920 & 4.21 & 1.00 & $\begin{array}{l}2.82 \mathrm{E}- \\
05\end{array}$ & SLITRK3 & 3_106218053 & -4.62 & 1.07 & $\begin{array}{l}1.64 \mathrm{E}- \\
05\end{array}$ & FHIT & 3_192239815 & -3.81 & 0.90 & $\begin{array}{l}2.31 \mathrm{E}- \\
05\end{array}$ & FGF12 \\
\hline 3_57173021 & 3.87 & 0.93 & $\begin{array}{l}3.75 \mathrm{E}- \\
05\end{array}$ & IL17RD & 3_106220437 & -4.29 & 1.02 & $\begin{array}{l}2.89 \mathrm{E}- \\
05\end{array}$ & LOC100302640 & 3_106219390 & -4.62 & 1.07 & $\begin{array}{l}1.64 \mathrm{E}- \\
05\end{array}$ & DOCK3 & 3_50996289 & 4.18 & 0.99 & $\begin{array}{l}2.55 \mathrm{E}- \\
05\end{array}$ & DOCK3 \\
\hline 3_120020489 & 3.73 & 0.90 & $\begin{array}{l}3.95 \mathrm{E}- \\
05\end{array}$ & LRRC58 & 3_59966975 & 3.58 & 0.86 & $\begin{array}{l}3.15 \mathrm{E}- \\
05\end{array}$ & FHIT & 3_106231571 & -4.54 & 1.05 & $\begin{array}{l}1.71 \mathrm{E}- \\
05\end{array}$ & $B C H E$ & 3_165049274 & 2.75 & 0.66 & $\begin{array}{l}3.35 \mathrm{E}- \\
05\end{array}$ & SLITRK3 \\
\hline 3_120023242 & 3.73 & 0.90 & $\begin{array}{l}3.95 \mathrm{E}- \\
05\end{array}$ & $\angle R R C 58$ & 3_192239815 & -5.47 & 1.31 & $\begin{array}{l}3.20 \mathrm{E}- \\
05\end{array}$ & FGF12 & 3_106232849 & -4.51 & 1.05 & $\begin{array}{l}1.86 \mathrm{E}- \\
05\end{array}$ & $B C H E$ & 3_165046402 & 2.71 & 0.66 & $\begin{array}{l}4.21 \mathrm{E}- \\
05\end{array}$ & SLITRK3 \\
\hline 3_108188993 & -3.77 & 0.91 & $\begin{array}{l}4.00 E- \\
05 \\
\end{array}$ & MYH15 & 3_192240010 & -5.28 & 1.27 & $\begin{array}{l}3.27 \mathrm{E}- \\
05 \\
\end{array}$ & FGF12 & 3_106220258 & -4.39 & 1.02 & $\begin{array}{l}1.86 \mathrm{E}- \\
05\end{array}$ & ZNF385D & 3_165053404 & 2.63 & 0.66 & $\begin{array}{l}6.83 \mathrm{E}- \\
05 \\
\end{array}$ & SLITRK3 \\
\hline 3_140640076 & 7.59 & 1.84 & $\begin{array}{l}4.08 \mathrm{E}- \\
05\end{array}$ & SLC25A36 & 3_72678387 & -4.30 & 1.04 & $\begin{array}{l}3.38 \mathrm{E}- \\
05\end{array}$ & SHQ1 & 3_106220368 & -4.45 & 1.05 & $\begin{array}{l}2.41 \mathrm{E}- \\
05\end{array}$ & MYH15 & 3_21520730 & 4.60 & 1.16 & $\begin{array}{l}7.82 \mathrm{E}- \\
05\end{array}$ & ZNF385D \\
\hline 3_158228266 & -4.87 & 1.18 & $\begin{array}{l}4.31 \mathrm{E}- \\
05\end{array}$ & $R S R C 1$ & 3_106218053 & -4.28 & 1.04 & $\begin{array}{l}4.20 \mathrm{E}- \\
05\end{array}$ & LOC100302640 & 3_72678387 & -4.53 & 1.07 & $\begin{array}{l}2.56 \mathrm{E}- \\
05\end{array}$ & $B C H E$ & 3_113652027 & 2.40 & 0.60 & 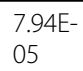 & $\overline{\text { GRAMD1C }}$ \\
\hline
\end{tabular}

*In the field "closest genes"; a bold gene name indicates that the SNP on the same row is right on that gene. 

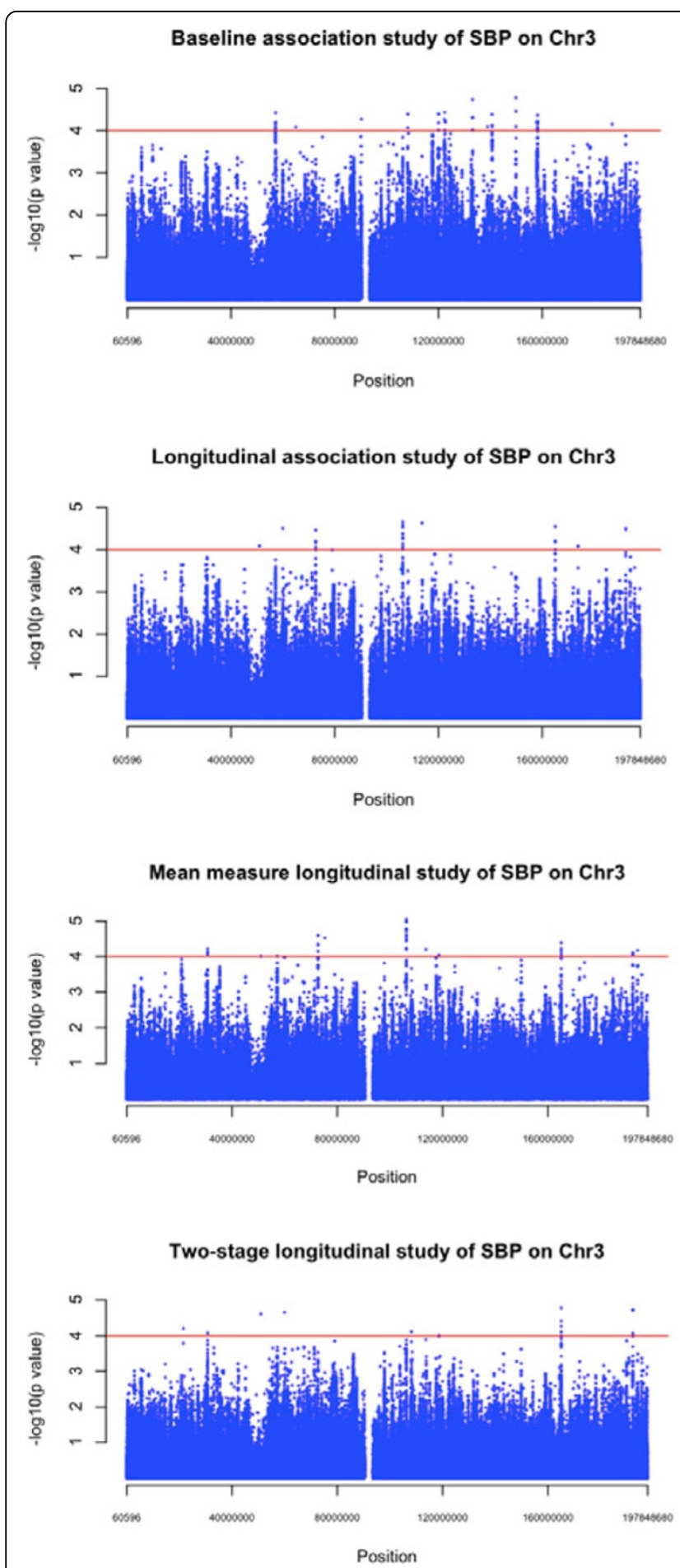
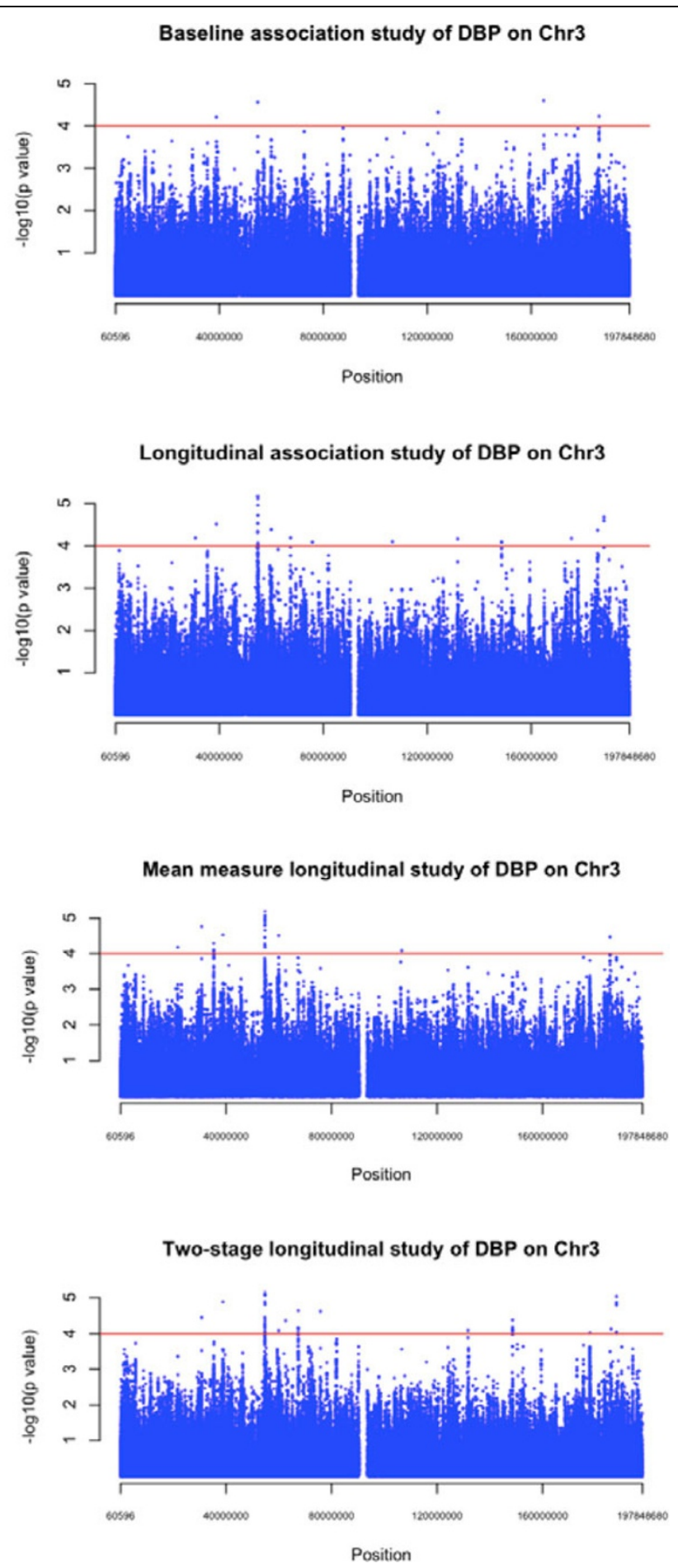

Figure 1 Manhattan plots on chromosome 3 using both the baseline and 3 longitudinal methods for SBP and DBP.

\section{Discussion and conclusions}

For both traits, the genes identified by the 3 longitudinal methods were consistent, but different from those found with the baseline approach. From the perspective of computational time, the mean measure and 2-stage methods were more computer efficient than the LME method. Furthermore, these 2 longitudinal methods were more powerful than the LME method. These 2 methods can act as efficient and powerful "substitutes" for LME. The mean measure method worked as well as 
Table 2 TOP 10 hits of DBP on chromosome 3 across the baseline method and the 3 longitudinal methods

\begin{tabular}{|c|c|c|c|c|c|c|c|c|c|c|c|c|c|c|c|c|c|c|c|}
\hline \multicolumn{5}{|l|}{ Baseline } & \multicolumn{5}{|l|}{ Longitudinal } & \multicolumn{5}{|c|}{ Mean-measure } & \multicolumn{5}{|l|}{ Two-stage } \\
\hline SNP & $\begin{array}{l}\text { Effect } \\
\text { size }\end{array}$ & SE & $P$ & $\begin{array}{l}\text { Closest* } \\
\text { genes }\end{array}$ & SNP & $\begin{array}{l}\text { Effect } \\
\text { size }\end{array}$ & SE & $\mathbf{P}$ & $\begin{array}{l}\text { Closest* } \\
\text { genes }\end{array}$ & SNP & $\begin{array}{l}\text { Effect } \\
\text { size }\end{array}$ & SE & $\mathbf{P}$ & $\begin{array}{l}\text { Closest* } \\
\text { genes }\end{array}$ & SNP & $\begin{array}{l}\text { Effect } \\
\text { size }\end{array}$ & $\mathrm{SE}$ & $\mathbf{P}$ & $\begin{array}{l}\text { Closest* } \\
\text { genes }\end{array}$ \\
\hline 3_164797024 & 4.98 & 1.17 & $2.48 \mathrm{E}-05$ & $S I$ & 3_54748234 & 2.20 & 0.43 & $\begin{array}{l}2.65 \mathrm{E}- \\
07\end{array}$ & CACNA2D3 & 3_54748234 & 2.23 & 0.44 & $\begin{array}{l}3.73 \mathrm{E}- \\
07\end{array}$ & CACNA2D3 & 3_54757032 & 1.10 & 0.21 & $\begin{array}{l}1.83 \mathrm{E}- \\
07 \\
\end{array}$ & CACNA2D3 \\
\hline $3 \_54748368$ & -2.15 & 0.51 & $2.76 \mathrm{E}-05$ & CACNA2D3 & 3_54757032 & 2.21 & 0.43 & $\begin{array}{l}3.21 \mathrm{E}- \\
07\end{array}$ & CACNA2D3 & 3_54757032 & 2.22 & 0.44 & $\begin{array}{l}5.77 \mathrm{E}- \\
07\end{array}$ & CACNA2D3 & 3_54748234 & 1.11 & 0.21 & $\begin{array}{l}2.39 \mathrm{E}- \\
07\end{array}$ & CACNA2D3 \\
\hline 3_124142019 & 2.85 & 0.69 & 4.62E-05 & KALRN & 3_547488368 & -2.15 & 0.42 & $\begin{array}{l}3.84 \mathrm{E}- \\
07\end{array}$ & CACNA2D3 & 3_54748368 & -2.17 & 0.43 & $\begin{array}{l}6.80 \mathrm{E}- \\
07\end{array}$ & CACNA2D3 & 3_54793253 & 1.05 & 0.21 & $\begin{array}{l}6.86 \mathrm{E}- \\
07\end{array}$ & CACNA2D3 \\
\hline 3_186144694 & -3.17 & 0.78 & 5.83E-05 & LOC253573 & 3_54784952 & 2.11 & 0.43 & $\begin{array}{l}7.90 \mathrm{E}- \\
07\end{array}$ & CACNA2D3 & 3_54793253 & 2.09 & 0.43 & $\begin{array}{l}1.67 \mathrm{E}- \\
06\end{array}$ & CACNA2D3 & 3_54799449 & 1.05 & 0.21 & $\begin{array}{l}7.79 \mathrm{E}- \\
07\end{array}$ & CACNA2D3 \\
\hline 3_38845381 & -3.68 & 0.91 & $6.06 \mathrm{E}-05$ & SCN10A & 3_54793253 & 2.08 & 0.42 & $\begin{array}{l}9.59 \mathrm{E}- \\
07\end{array}$ & CACNA2D 3 & 3_54784952 & 2.09 & 0.44 & $\begin{array}{l}2.05 \mathrm{E}- \\
06\end{array}$ & CACNA2D3 & 3_54784952 & 1.05 & 0.21 & $\begin{array}{l}7.90 \mathrm{E}- \\
07\end{array}$ & CACNA2D3 \\
\hline 3_186209848 & -3.05 & 0.78 & 0.000107 & LOC253573 & 3_54779240 & 2.08 & 0.43 & $\begin{array}{l}1.04 \mathrm{E}- \\
06\end{array}$ & CACNA2D3 & 3_54799449 & 2.09 & 0.44 & $\begin{array}{l}2.31 \mathrm{E}- \\
06\end{array}$ & CACNA2D3 & 3_54748368 & -1.05 & 0.21 & $\begin{array}{l}8.15 \mathrm{E}- \\
07\end{array}$ & CACNA2D3 \\
\hline 3_87619500 & 2.32 & 0.60 & 0.000109 & POU1F1 & 3_54756448 & -2.10 & 0.43 & $\begin{array}{l}1.07 \mathrm{E}- \\
06\end{array}$ & CACNA2D3 & 3_54756448 & -2.09 & 0.44 & $\begin{array}{l}2.35 \mathrm{E}- \\
06\end{array}$ & CACNA2D3 & 3_54779240 & 1.03 & 0.21 & $\begin{array}{l}9.61 \mathrm{E}- \\
07\end{array}$ & CACNA2D 3 \\
\hline 3_177961323 & -2.05 & 0.53 & 0.000115 & $\begin{array}{l}\text { KCNMB2- } \\
\text { IT1 }\end{array}$ & 3_54756196 & 2.06 & 0.43 & $\begin{array}{l}1.46 \mathrm{E}- \\
06\end{array}$ & CACNA2D 3 & 3_54756196 & 2.08 & 0.44 & $\begin{array}{l}2.48 \mathrm{E}- \\
06\end{array}$ & CACNA2D3 & 3_54807320 & 1.03 & 0.21 & $\begin{array}{l}9.67 \mathrm{E}- \\
07\end{array}$ & CACNA2D3 \\
\hline 3_72651668 & 2.05 & 0.53 & 0.000132 & SHQ1 & 3_54793450 & -2.07 & 0.43 & $\begin{array}{l}1.57 \mathrm{E}- \\
06\end{array}$ & CACNA2D 3 & 3_54747244 & 2.07 & 0.44 & $\begin{array}{l}2.65 \mathrm{E}- \\
06\end{array}$ & CACNA2D 3 & 3_54756196 & 1.03 & 0.21 & $\begin{array}{l}1.26 \mathrm{E}- \\
06\end{array}$ & CACNA2D 3 \\
\hline 3_186149493 & -3.04 & 0.79 & 0.000134 & LOC253573 & 3_54740011 & 2.05 & 0.43 & $\begin{array}{l}1.75 \mathrm{E}- \\
06\end{array}$ & CACNA2D 3 & 3_54740011 & 2.07 & 0.44 & $\begin{array}{l}2.67 \mathrm{E}- \\
06\end{array}$ & CACNA2D 3 & 3_54799706 & 1.02 & 0.21 & $\begin{array}{l}1.27 \mathrm{E}- \\
06\end{array}$ & CACNA2D3 \\
\hline
\end{tabular}

*In the field "closest genes"; a bold gene name indicates that the SNP on the same row is right on that gene. 
Table 3 Power calculation of all 4 methods (based on the 200 simulations)

\begin{tabular}{lllll}
\hline Method & Baseline & Mean measure & Two-stage & LME \\
\hline Power & $22 \%$ & $41 \%$ & $40.5 \%$ & $32.5 \%$ \\
\hline
\end{tabular}

the 2-stage method, identifying the same genes. The signals found with the 2-stage method (third row of Manhattan plot in Figure 1) were almost identical to those with the LME method, for both SBP and DBP. Therefore, we concluded that the mean measure and 2-stage methods were 2 efficient ways to analyze longitudinal data when the goal is to examine level of a trait. Only the longitudinal approach can evaluate associations with trends over time.

\section{Competing interests}

The authors declare that they have no competing interests.

\section{Authors' contributions}

SW, WG, JN, CA, CTL, LAC designed the overall study, SW, WG, JN, CA conducted statistical analyses and SW, WG, JN drafted the manuscript. All authors read and approved the final manuscript.

\section{Acknowledgements}

The research was conducted using Linux Clusters for Genetic Analysis (LinGA). The computing resource was funded by the Robert Dawson Evans Endowment of the Department of Medicine at Boston University School of Medicine and Boston Medical Center, the National Heart, Lung and Blood Institute contract to the Framingham Heart Study (N01-HC-38038), and contributions from individual investigators. The GAW18 whole genome sequence data were provided by the T2D-GENES Consortium, which is supported by NIH grants U01 DK085524, U01 DK085584, U01 DK085501, U01 DK085526, and U01 DK085545. The other genetic and phenotypic data for GAW18 were provided by the San Antonio Family Heart Study and San Antonio Family Diabetes/Gallbladder Study, which are supported by $\mathrm{NIH}$ grants P01 HL045222, R01 DK047482, and R01 DK053889. The Genetic Analysis Workshop is supported by NIH grant R01 GM031575.

This article has been published as part of BMC Proceedings Volume 8 Supplement 1, 2014: Genetic Analysis Workshop 18. The full contents of the supplement are available online at http://www.biomedcentral.com/bmcproc/ supplements/8/S1. Publication charges for this supplement were funded by the Texas Biomedical Research Institute.

\section{Authors' details}

${ }^{1}$ Department of Biostatistics, Boston University School of Public Health, 801 Massachusetts Avenue 3rd floor, Boston, MA 02118, USA. Département de Mathématiques, Université de Sherbrooke, Québec, Canada J1K 2R1.

Published: 17 June 2014

\section{References}

1. Zhu W, Cho K, Chen X, Zhang M, Wang M, Zhang H: A genome-wide association analysis of Framingham Heart Study longitudinal data using multivariate adaptive splines. BMC Proc 2009, 3(suppl 7):S119.

2. Luan J, Kerner B, Zhao JH, Loos RJ, Sharp SJ, Muthén BO, Wareham NJ: A multilevel linear mixed model of the association between candidate genes and weight and body mass index using the Framingham longitudinal family data. BMC Proc 2009, 3(suppl 7):S115.

3. Smith EN, Chen W, Kähönen $M$, Kettunen J, Lehtimäki T, Peltonen L, Raitakari OT, Salem RM, Schork NJ, et al: Longitudinal genome-wide association of cardiovascular disease risk factors in the Bogalusa Heart Study. PLoS Genet 2010, 6:e1001094.
4. Gauderman WJ, Macgregor S, Briollais L, Scurrah K, Tobin M, Park T, Wang D, Rao S, John S, Bull S: Longitudinal data analysis in pedigree studies. Genet Epidemiol 2003, 25(Suppl 1):S18-S28.

5. R Development Core Team: A language and environment for statistical computing. R Foundation for Statistical Computing, Vienna, Austria; 2009 [http://www.R-project.org].

6. R Development Core Team: A language and environment for statistical computing. R Foundation for Statistical Computing, Vienna, Austria; 2012 [http://www.R-project.org].

7. Laird NM, Ware JH: Random-effects models for longitudinal data. Biometrics 1982, 38:963-974.

8. Purcell S, Neale B, Todd-Brown K, Thomas L, Ferreira MA, Bender D, Maller J, Sklar P, de Bakker PI, Daly MJ, et al: PLINK: a tool set for whole-genome association and population-based linkage analyses. Am J Hum Genet 2007, 81:559-575.

\section{doi:10.1186/1753-6561-8-S1-S84}

Cite this article as: Wang et al: Comparing baseline and longitudinal measures in association studies. BMC Proceedings 2014 8(Suppl 1):S84.

\section{Submit your next manuscript to BioMed Central and take full advantage of:}

- Convenient online submission

- Thorough peer review

- No space constraints or color figure charges

- Immediate publication on acceptance

- Inclusion in PubMed, CAS, Scopus and Google Scholar

- Research which is freely available for redistribution 